\title{
GENERAL DISCUSSION ON PAPERS
}

\author{
By Dr P. Minaire et al., M. Price, P. Almagro et al., Ravichandran and \\ Silver, and NUSEIBEH and BURR.
}

Subject. Life Expectancy following Spinal Cord Injury.

Chairman. Professor W. Paeslack.

Dr R. Facobs. (U.K.). I would like to take up the subject of the very disturbing number of suicides which have figured in several of the papers that we have just heard. Regarding the possible factors which may be contributing to these suicides I wish to ask the speakers if they can provide us with any information about the length of hospital stay of these particular patients. I know that some people believe that patients' ability to cope with their situation after discharge may well be related to their initial stay in hospital and this may be a variable that we are not tying up sufficiently with this particular issue.

$\operatorname{Dr} W$. Geisler. (Canada). In the study which was reported in 1977 in Paraplegia, we reported the incidence of suicide but I cannot remember the figure, but the numbers have now almost doubled. In 1977, we noted that suicide occurred some 10 years or more after the predominant peak epidemiology of the onset of the disease, which led us to believe that it was not an impulsive act on the part of the patient but that it took some time for him to reach the decision. I would like to mention a rather poignant point: there were seven suicides in the current group who were all young. We suspect that suicide may be preventable. There is a great exaltation that all of us might be willing to accept that mortality seems to be reduced, and life expectancy seems to be increased, but there is a great responsibility for all of us involved in the field of paraplegia. The despondency and loss of spirit that comes to these people both in the early stages and all too often in the later stages of paraplegia, may not be obvious in someone who has given no indication that 'his lot is beginning to wear out'. There are consequences that everyone must pay for being paraplegic. It is highly unlikely that paraplegics will live as long as those who are not paraplegic, and we feel that as far as suicide is concerned it behoves you and I working in the field of paraplegia to spend as much time as we can in counselling these persons again and again. There must be someone who is willing to sit down and to talk with them when things are going wrong. Things went well during the first 10 or 15 or 20 years but then the syndrome which my colleague Dr Al Jousse has coined and talked about the 'burned-out' syndrome of the paraplegic, and not only the paraplegic, nor of other disabled persons, but of society at large, but particularly prevalent in the paraplegic. That may be the most significant contribution that those of us who are committed to the care of paraplegics will have to accept in the years that lie ahead now that we are curing renal disease and treating cardiac arrest.

Dr Pinkerton. (Canada). I want to ask Dr Geisler (paper read, but not offered for publication) whether the patients that committed suicide in his study were tetraplegics or paraplegics. In our study covering a period of 5 years plus 2 years follow-up, half of the deaths are from suicides, and two other deaths may be from suicide, and that is just out of ten deaths. All were paraplegic.

$\mathrm{Dr}$ Geisler. Our experience is not the same as that of Dr Pinkerton's: our patients who committed suicide include both paraplegics and tetraplegics.

$\operatorname{Dr}$ Young. (U.S.A.). We have heard from Dr Minaire that the death rate seems to plateau off after the first year, and Dr Hardy suggests that it continues 
and does not plateau up to the tenth year. Would Dr Geisler please comment?

Dr Geisler. Our experience would be more in line with Dr Hardy's experience.

Col Chahal. (India). Dr Price what is the suicide rate in the 'normal' population of Minnesota? Out of the 550 paraplegics we have seen during the last Io years in India, only one patient threatened to commit suicide, but did not. So I feel that what is important is the philosophy of life. There is something to learn from developing countries, that it is the philosophy which matters rather than constant counselling. Many friends from America and Europe go to India to learn about Indian philosophy, and that is the fate, the god, accept it and then try to live with it, rather than trying to challenge God.

Dr M. Price. (U.S.A.). In answer to Dr Chahal, I do not know what the suicide rate is in Minnesota, but I understand that it is lower than in many States in the Union, we are largely (I am not included in this) of Scandinavian stock, a very stoic people who handle life very well. We did find that two of our patients had had their injury only one year, one 2 years and the remainder 7 to 10 , before committing suicide.

$\operatorname{Dr} A$. Key. (S. Africa). I agree with Col Chahal. We have had 2600 patients treated in the Spinal Unit in Capetown, and there have been three suicides. I wish to ask Dr Price about the remarkably low death rate from renal failure; has renal dialysis played any part in this?

Dr Price. I would say that only one of our patients would have been considered for dialysis according to current standards, and this is a patient who had a GFR of 4 square metres per minute, which would have been about 6 using the creatinine clearance standards for $\mathrm{I} \cdot 73$.

Dr Silver. (U.K.). I would like to know when the patients were admitted. The reason I make this point is that if you admit patients immediately then you are going to have quite a high initial mortality from patients who require to be on a ventilator. If the patient is admitted even a week or 2 or 3 weeks after injury, it may be that severe $\mathrm{C} 4$ lesion patients will no longer be represented in the various series. But such patients who have an early tracheostomy with a very small vital capacity or perhaps a litre or a litre and a half, are always going to be at risk of dying quite suddenly of upper respiratory tract infection once they leave hospital, so that they may die within 12 hours. Therefore to compare different series, we require to know how quickly they were admitted, the initial mortality, and the level of the cervical lesion.

Dr Blumenthal. (Germany). Dr Price told us of one patient who had renal failure and gave up life: I have a semantic difficulty: did the renal failure cause chronic suicide?

Dr Price. I am certain that in this young man it was a chronic suicide. I think in the others, the patient with tubular acidosis, the sociopathic Indian man, the woman I did not know very well and certainly the man who died of gram negative septicaemia definitely died from suicide, but could not be listed, therefore we cannot prove it.

Dr Frankel. (U.K.). I have admired Dr Geisler's and his associates work and publications over the years because they have been the best available to us for certain purposes. But we are not told how the figures are derived, and it does appear in all previous publications that although they were matched for age, they were then turned into a global figure and each individual was then multiplied by the same factor. This is obviously the simplest way of analysing and studying the material, as it is easy to understand, but I wonder if they do not have the actual information available to tell us more so that we can know exactly how their life expectancy in each age group is derived. It is by multiplying the expected death rate from that group by a factor, and the same factor for each age, or are they using the correct factor for each age group?

Dr Geisler. I appreciate that criticism and we are going to try and correct it in the final publication. It involves numbers, individual age groups and levels, 
and to overcome that hurdle a little, we have grouped them into general groups rather than the singular age group.

Dr Bruno (Italy). I do not know if we have the same influence as in India, in North Italy, or the same way of life, but in about 2000 patients that I have treated I have only known of one suicide; it occurred this year: a man of 68 who has been paraplegic for 35 years. He was living with his wife, who died, and then he lived alone. I would say that he would probably have committed suicide even if he was not paraplegic. A young man of $\mathrm{I} 6$ in my hospital attempted suicide by trying to cut a vein with a safety razor.

Chairman. Dr Almagro and Dr Mendoza: regarding the deaths that you reported did you include those who died after discharge, or were they patients who died during their stay in the hospital? You reported about 12 cases of massive pulmonary embolism, seven with deep venous thrombosis, and about 29 cases of cardio-pulmonary arrest. Do you use prophylactic anticoagulant therapy; when and in which way?

Dr Mendoza. (Spain). Regarding your first question, ours is the only hospital, the situation is quite difficult in Spain, in some areas it is very difficult to obtain answers to questions. The information may only be obtained during hospitalisation. Anticoagulant therapy is used in the usual way. We usually use heparin within 24 hours of injury, excluding as usual patients who have active haemorrhage. 